\title{
TANTANGAN DAN MODEL PENDIDIKAN SEJARAH DI ERA MILENIAL
}

\author{
I Made Pageh \\ Email : madepagehundiksha@gmail.com
}

Jurusan Sejarah UNDIKSHA

\begin{abstract}
Abstrak
Pendidikan sejarah dipahami hanya merupakan pendidikan rethingking (reflektif thinking). Nietzche melontarkan, bahwa sejarah hanya semacam bayangan nostalgia dari orang-orang yang sudah kehilangan keyakinan diri dan semangat hidup masa kini (cf. Carr, 1972:29). Oleh karena itu pendidikan sejarah menarik dikaji era milinal ini, dikaitkan dengan era teknologi informatika dan industri 4.0 yang diwarnai oleh computer-awan dan industri otomatisasi. Dalam kajian beberapa ahli futurelog masih memberikan peluang pada pendidikan sejarah untuk hidup, terutama agar manusia tidak kehilangan kemanusiaannya, rasa waktu di era milinial. Untuk dapat hidup pendidikan sejarah harus dapat beradaptasi dengan jiwa dan budaya zaman milinial, dengan mengikuti trend zamannya. Kalau tidak mau ditinggalkan, atau dipandang hanya sebagai beban kurikulum saja. Jika sejarah dapat mengikuti zaman komputasi awan dan industri 4.0, sejarah menjadi sangat kaya dengan materi yang dapat komudifikasikan secara kreatif dan inovatif, melalui pemikiran hibridasi masa lalu ,masa kini, dan masa depan. Pembelajaran sejarah di era milinial harus dilengkapi dengan kemampuan literasi big bank data, literasi teknologi komputasi awan, dan literasi kemanusiaan. Literasi kemanusiaan, kebangsaan, kearifan lokal dapat dikemas menjadi bagian dunia melalui hibridasi dalam glokalisasi. Pembelajaran sejarah harus segera melakukan reorientasi ke masa depan seperti era komputasi awan dan industri 4.0, sehingga pendidikan sejarah dapat menjadi komuditas unggulan dalam industri kreatif dan industri otomatisasi di masa depan.
\end{abstract}

Kata Kunci: Model Pendidikan Sejarah, Komputasi Awan, Industri Otomatisasi, era milenial.

\section{Pendahuluan}

Komputasi awan merupakan istilah untuk memadukan komputer dengan internet, yang mendasari otomatisasi jaringan yang disebut juga industri 4.0, di era mileneal ini. Perkembangan teknologi produksi/industri dapat dirunut sebagai berikut: (1) mekanisasi tenaga air (steam power); (2) mass production (assemble line electricity); (3) computer and automation; dan (4) cyber physical system. Tulisan ini ingin memberikan gambaran peranan computer and internet dalam pembelajaran sejarah di era milenial. Industri otomatisasi melalui dunia maya yang menjadi trend di masyarakat, dikenal dengan industri 4.0.

Perkembangan Tekonologi Informatika terjadi begitu cepat di tahun 1950-an komputer masih merupakan mesin raksasa, sepuluh tahun kemudian tahun 1960-an dengan ditemukannya 267 | Seminar Nasional Sejarah ke 4 Jurusan Pendidikan Sejarah Universitas Negeri Padang 
artificial intlegence pada tahun 2000-an Teknik Informatika mengalami revolusi dalam computer setelah dilakukan hibridasi dari computer, internet, telpon, radio dan TV menjadi disambungkan dengan disediakan berbagai alat selusurnya untuk menemukannya di dalam big bank data (komputasi awan) ${ }^{1}$. Perubahannya dapat dihitung tidakmembutuhkan waktu lama, dengan disediakannya big bank data as open source, dalam 10 tahun terakhir terjadi revolusi otomatisasi (industri 4.0), lahir pertama di Jerman pada tanggal 8 April 2013, dalam jangka waktu enam tahun (2019) ini dapat dilihat perkembangannya yang sangat luar biasa. ${ }^{2}$

Dari persektif kultural kehidupan manusia era milenial ini diwarnai ciri-ciri utama masyarakat post-modern yang serba melampaui. Secara reflektif sosok manusia modernitas menjadi semakin materialistis, legalistis, formalistis, hedonis, dan penuh pencitraan bahkan kehidupan diwarnai oleh simulacra atau kesadaran palsu (cf. Piliang, 2010). Ramalan Tofller sudah menjadi kenyataan bahwa "hidup menjadi drama pencitraan", instrumental, kehilangan jati diri kemanusiaan, karena diganti dengan intlegence artificial di era milenial ini. Pendidikan sejarah yang bersifat reflektif tinking dalam gambaran masa depan, pernah dilontarkan Nietzche (filsuf posmodernisme) bahwa sejarah hanya semacam bayangan nostalgia orang-orang yang kehilangan keyakinan diri dan semangat hidup (cf. Carr, 1972:29). Dari gambaran masa depan yang demikian itu, pendidikan sejarah menjadi masalah dalam kurikulum pendidikan, sehingga menarik untuk dikaji, dengan beberapa masalah: (1) apakah tantangan pendidikan sejarah di era milenial?; (2) apakah peranan pendidikan sejarah masih dibutuhkan?. Jika masih dibutuhkan muncul pertanyaan lanjutan (3) "model pendidikan sejarah yang bagaimana diperlukan di era milenial itu?".

Setiap anak zaman akan menjawab masalah dan tantangan budaya zamannnya, dengan demikian pertanyaan ini hakikatnya merupakan pertanyaan klasik, karena setiap anak zaman akan merumuskan pertanyaan yang sama, dan memberikan jawaban alternatif berbeda sesuai dengan zeitgeist dan cultuurgebudenheid (alikan gumi) zamannya (cf Colingwood, 1980; Pirenne, 1959; Ankersmit, 1987; Adam, 2009).

\footnotetext{
${ }^{1}$ Komputasi awan adalah penggabungan antara komputer dan internet (cloud computing) layanan sistem computer, seperti utility public yang dapat diakses secara cepat melalui internet.

2 Industri 4.0 dengan tifologi otomatisasi yang bertumpu pada kecerdasan artificial dan komputasi awan dengan model Jerman (sejak 2013), kini Jepang menentangnya karena mengabaikan kecerdasan manusia, dan manusia menjadi alat/disamakan dengan mesin slusur dengan tetap bertumpu pada manusia dibantu oleh komputasi awan, disebut industri 5.0. yaitu industri 4.0 ditambah dengan literasi kemanusiaan yang mengendalikannya.
} 
Pertanyaan ini dirumuskan yang datanya diambil dari sub tema disertasi penulis (Pageh, 2016) akan didiskusikan secara runut dengan menambahkan data diambil dari studi pustaka, big data dunia maya, dan pemahaman kritis situasi pendidikan sejarah yang sedang berlangsung. Dengan perspektif teknologi komputasi-awan dan industri otomatisasi (revolusi industri 4.0) diadaptasikan dengan sejarah sebagai komuditas dalam pendidikan di era milenial.

\section{Tantangan Pendidikan Sejarah di Era Milenial}

Pendidikan sejarah memiliki dimensi masa lalu, masa kini dan masa depan. Pendidikan sejarah diharapkan dengan mempelajari masa lalu untuk menghadapi masa kini dan memetakan masa depan (Wineburg, 2006). Gambaran masa depan pernah dibayangkan Alvin Toffler di bidang pendidikan (Toffler 1970: 360-386) 18 tahun silam, dia sangat menekankan perubahan teramat cepat dialami umat manusia dengan berbagai jaringan dan institusinya, termasuk jaringan institusi pendidikan. Demikian cepat perubahan itu, sekolah-sekolah dianjurkan Toffler untuk membangun "super-industrial education system", dengan demikian kurikulum dibuat mengacu pada bentuk-bentuk perubahan yang sangat cepat itu. Sebagai konsekuensinya, mata pelajaran yang tujuan, materi, serta kompetensi yang tidak sesuai dengan ikip-ciri gambaran masa depan di atas, perlu dicopot dari kurikulum, karena hanya akan menjadi beban dalam pendidikan.

Pertanyaannya apakah pendidikan sejarah yang dipahami hanya "bersifat reflektif tinking, meditative study" harus disingkirkan dari kurikulum? Ternyata futurlog Toffler menjawab dengan tegas tidak, bahkan memberikan penguatan bahwa pendidikan sejarah justru sangat penting untuk ditawarkan, karena sejarah intinya penanaman time sense dalam kehidupan manusia, yang sangat dipentingkan pada era milenial seperti yang dibayangkan Toffler. Tanpa sejarah orang akan menjadi kehilangan orientasi temporal atau rasa waktu. ${ }^{3}$ Namun yang dikritik oleh Toffler adalah pelajaran sejarah umumnya yang hanya berorientasi ke masa silam dengan penekatan kognitif atau factual saja. Dengan demikian dalam pembelajaran sejarah dibutuhkan reorientasi dalam belajar masa lalu untuk memahami masa kini dan memetakan masa depan manusia (cf. Wineburg, 2006), terutama era milenial. Pada hal untuk mengantisipasi dan

\footnotetext{
${ }^{3}$ Hubungan waktu, struktur, dan agensi diulah oleh Anthony Giddens dalam teori Strukturasi (lihat Giddens, 2010).
}

269 | Seminar Nasional Sejarah ke 4 Jurusan Pendidikan Sejarah Universitas Negeri Padang 
menghadapi tantangan masa depan yang serba cepat, perlu ditanamkan sense of the future time dengan berbagai antisipasinya. Kebutuhan peserta didik bukanlah masa lalu dan masa kini saja, tetapi perlu diajarkan sejarah ikipe secara kritis untuk menghadapi tantangan era komputasi awan dan industri otomatisasi di masa depan. Sejarah memiliki perspektif kesadaran waktu dan kontinuitas kebudayaan, yang kalau diabaikan, dapat menyebabkan manusia terkungkung oleh kemasakinian yang ikipediae dan penuh ikipedia atau kesadaran palsu (Budrilard dalam Piliang, 2010). Merujuk masa depan sebagai keinsyafan, kesadaran, dan sebagainya banyak ahli mengemukakan pandangannya. Bagaimana tindak lanjutnya tidak banyak yang memberikan petunjuknya. Dasar hakiki eksistensi manusia adalah kontinuitas dan diskontinuitas yaitu perubahan dan peralihan terus menerus menuju masa depan yang lebih baik (Meulen 1987:83).

Salah satu ikipediae jawaban tercermin pada tulisan Von Laue yang berjudul "What history for the year 2000? (1981:7). Dia bertolak dari masalah besar yang sedang menghadang para sejarawan yang digambarkan "have lost their former consensus over priorities and basic meaning in their work". Para sejarawan, katanya terlalu terpaku pada hal-hal detail yang melebar ke segala aspek kehidupan, dengan mengorbankan pertimbangan prioritas bagi masa sekarang dan masa yang akan datang, sehingga hanya menghasilkan "Splintered History" (serpihan sejarah). Sejalan denganpikiran ini pendidikan sejarah, bermakna "mendorong lahir kepicikankepicikan pandangan peradaban yang etnosentrisme serta egosentrisme seperti tercermin pada pengajaran sejarah dalam rangka social studies. Untuk menghadapi kenyataan ini katanya diperlukan " $a$ detached comprehensive historical understanding of the present world that sustains us in our material existence". Sejarah macam ini disebut "all inclusive historical perspective" atau "global historical perspective" yang didukung oleh moralitas yang menembus batas-batas nilai yang berorientasi pada kelompok-kelompok eksklusif yang sudah mapan (Cf. Widja, 2017).

Pendidikan sejarah di Indonesia tidak dapat mengabaikan ikipe tanah airnya, karena peran utamanya adalah untuk kesadaran nasional dan kearifan lokal. Kalau dilihat dari pandangan Anthony Giddens (2010) Sejarah adalah ilmu sosial yang terkait dengan peristiwa manusia (agensi), temporal-kontekstual, dan struktur (budaya nasional dan lokal). Konteks muatan ikipedi seperti Pancasila dan Trihita Karana adalah menyangkut behavioristik, tatanan berpikir, dan bertindak. Bayangan penulis justru akan menjadi keunggulan di masa depan, karena kearifan nasional dan lokal dapat mewarnai dalam pergaulan dunia (global). Dalam literasi 270 | Seminar Nasional Sejarah ke 4 Jurusan Pendidikan Sejarah Universitas Negeri Padang 
kemanusiaan (kesetiakawanan umat manusia) memiliki dimenasi relasi manusia dengan tuhannya (good name every tink), manusia dengan manusia (humanities religious), dan manusia dengan lingkungan alam yang lestari (save the world). Maka sangat memungkinkan adanya hibridasi peradaban internasional dengan regional sehingga tumbuh peradaban dunia baru yang bersifat hibridasi global dengan lokal, antara "Arjuna dengan Paus".

Secara singkat dapat dikatakan bahwa pendidikan sejarah masih diperlukan di era disrupsi teknologi dan industri otomatisasi di masa depan. Namun dengan melakukan reorientasi dalam pembelajarannya dengan model pembelajaran inovatif konstruktif. Pertanyaannya sekarang adalah "model pendidikan sejarah yang bagaimana diperlukan di era masa depan itu?" Hal inilah yang sangat penting dicarikan model ikipediae dalam pendidikan sejarah ysng konstruktif, sesuai dengan situasi perubahan serba cepat, industri serba digital dan mengglobal di era milenial

\section{Kesadaran Sejarah dan Nation Building}

Masalah penting selanjutnya untuk menyongsong perubahan di masa depan?” Untuk itu akan ditinjau pertama-tama pandangan Von Laue (1981) dan Toynbee (1946) yang menekankan sejarah global, terutama dalam garis pikiran yang kurang ikipe tempat pada sejarah nasional, apalagi sejarah lokal, yang dicurigainya sebagai sumber sikap etnosentrisme (Widja, 1991).

Seperti kita ketahui makna pengalaman masa lampau bagi suatu masyarakat adalah untuk pertumbuhan kesadaran kolektif yang menjadi dasar pertumbuhan kepribadian nasional (Kartodirdjo, 1987:205); Fitzgerald,1983:62). Proses pertumbuhan ke kepribadian nasional melalui pengalaman serta kesadaran kolektif ini kiranya berlaku bagi semua bangsa, hanya saja ada bangsa-bangsa yang merasakannya secara lebih sadar serta sebagai kebutuhan yang lebih mendasar. Ini rupanya tergantung dari pengalaman masa lampau masing-masing bangsa. Ada bangsa-bangsa, seperti umumnya bangsa-bangsa di dunia barat, yang merasakan penemuan identitas kenasionalan itu sebagai pertumbuhan yang wajar dari pengalaman masa lampaunya.

Sedangkan bagi bangsa-bangsa terjajah, kelihatannya kesadaran ini tumbuh dan terkait dengan pengalaman traumatis akibat kehilangan kemerdekaan yang dirampas oleh bangsabangsa penjajah. Oleh karena itu, bagi bangsa terjajah seperti bangsa Indonesia, pengalaman kolektif menuju kesadaran identitas nasional adalah satu kebutuhan mendasar, bahkan satu keharusan agar mereka bisa kembali mewujudkan jati dirinya dan menempati posisi yang wajar 
dalam pergaulan antar bangsa di dunia ini. Atas dasar jalan pikiran di atas ini, sulit dibayangkan bagi bekas bangsa-bangsa terjajah, termasuk Indonesia, dapat begitu saja mengabaikan sejarah nasionalnya,karena sejarah nasional merupakan basis kekuatan bangsa pernah terjajah (sifat nasionalitasnya). Bisa saja sejarah global dikembangkan, tetapi sejarah global harus dilihat sebagai perluasan wawasan sejarah nasional, bukan untuk menggantikannya. Ini berarti pula, bagi bangsa Indonesia, sejarah nasional adalah tempat menggali simbol integritas serta kekuatan ideal sebagai suatu bangsa, akan tetap memegang peranan penting di masa depan, tanpa mengabaikan arti penting sejarah global maupun sejarah lokal.

Selain masalah unit studi, perlu juga dipertanyakan arah dan sasaran pendidikan sejarah yang bagaimana yang perlu ditekankan dalam menyongsong revolusi terakhir? Pembelajaran abad XXI memiliki beberapa ikip: (1) life and career skills; (2) Inovasi pembelajaran yang mengarahkan peserta didik miliki 4 ciri utama yaitu: berpikir kritis, komunikasi, kerjasama, dan kreativitas. (3) Memanfaatkan informasi, media, dan ketrampilan teknologi. (4) Standard and accessments; (5) Kurikulum dan pembelajaran; (6) pengebangan profesionalisme; (7) pengembangan lingkungan belajar. Di sinilah pendidikan sejarah agar tidak menjadi beban harus mampu mengikuti pekembangan zamannya (zeitgeist and cultuurgebudenheid).

Barat sendiri terus berdebat, seperti pandangan James Fitzgerald "History in the curriculum: Debate on Aims and Values" (Fitzgerald, 1983). Di Amerika Serikat terjadi perdebatan sengit antara Edwin Fenton (1966) dan Mark Krug (1967). Fenton, dengan "inquiry approach"nya dalam pendidikan sejarah, kelihatannya diilhami oleh pikiran-pikiran Bruner dan Bloom dalam psikologi belajar. Dalam pendekatan ini sangat ditekankan ikipe-unsur konsep, struktur serta metodologi dalam pelajaran sejarah. Sedangkan Krug mengeritik tajam pandangan Fanton ini, dengan menegaskan "The value of history is not scientific. Its true value is educational. It can educate the minds of men by causing them to reflect them on the past" (Krug, 1967:26). Pembelajaran sejarah membutuhkan pemikiran baru ke luar dari paradigma lama dalam pembelajaran yang hanya demi pembangunan nasionalisme dan kearifan lokal, tetapi dibutuhkan pembangunan kesadaran sejarah kritis, antisipatif, terhadap jiwa zaman digitalisasi terutama industri 4.0 di era milenial.

Perhatian utama yang perlu diperhatikan dalam pendidikan sejarah ialah harapan untuk ikut berperan dalam pembangunan nasional demi mencapai cita-cita masa depan Indonesia. Arah 
dan tujuan pendidikan sejarah mesti mengandung usaha meningkatkan kepekaan anak untuk ikut menunjang kesadaran nasional dan lokal dalam kehidupan bersama yang multikultur. Tentu saja ini sejalan pula dengan latar belakang psikologis sejarah nasional sebagai obsesi membangkitkan harga diri demi harkat dan martabat bangsa dalam pergaulan masyarakat dunia. Namun, perlu disadari sisi lemah pendidikan sejarah macam ini, yaitu mudah jatuh ke sifat linier, ekstrinsik, dan instrumental relasi-kuasa dan melemahkan perkembangan daya kritis anak. Sejarah sering mengarah menjadi "alat cetak" untuk membentuk manusia yang sudah ditentukan sebelumnya (predefined person) atau bersifat indoktrinasi. Menekankan terlalu berlebihan aspek instrumental dari pendidikan sejarah, bukan saja akan menyebabkan timbulnya gambaran proses yang pasif reseptif, tetapi juga apa yang dikatakan Sartono Kartodirdjo sebagai proses "entropy”, suatu proses organis yang menunjukkan kehidupan tanpa perkembangan (involusi) (Kartodirdjo,1987:245; Scoot, 1987).

\section{Model Pendidikan Sejarah di Era Komputasi Awan dan Industri Otomatisasi}

Sejarah wajib mengikuti dan mengadaptasi semangat teknologi dan industri otomatisasi (industri 4.0). Dengan demikian instrument pendidikan sejarah harus disesuaikan dengan situasi up to date seperti: (1) Kurikulumnya memberikan peluang mengikuti teknologi Komputasi awan dan industri 4.0; (2) Pembelajaran dan metodologi pembelajarannya berbasis teknologi informatika; (3) Sumber belajar, menggunakan open source; (4) persyaratan berupa inprastruktur dan teknologi komputasi awan; (6) Butuh lembaga jaminan mutu. Bagian-bagian pendidikan ini merupakan keharusan untuk diantisipasi ke depan.

Industri 4.0 adalah nama tren otomatisasi dan pertukaran data terkini dalam teknologi pabrik. Istilah ini mencakup sistem siber-fisik, internet untuk segala, komputasi awan (computer dan internet) dan komputasi kognitif. Industri 4.0 menghasilkan "pabrik cerdas". Di dalam pabrik cerdas berstruktur moduler, sistem siber-fisik mengawasi proses fisik, menciptakan salinan dunia fisik secara virtual, dan membuat keputusan yang baik terpusat. Lewat interbet untuk segala (IoT), sistem siber-fisik berkomunikasi dan bekerja sama dengan satu sama lain dan manusia secara bersamaan. Lewat komputasi awan layanan internet dan lintas organisasi disediakan dan dimanfaatkan oleh berbagai pihak dalam rantai nilai (https://id.wikipedia.org/ wiki/Komputasi_awan).

273 | Seminar Nasional Sejarah ke 4 Jurusan Pendidikan Sejarah Universitas Negeri Padang 
Dalam pembelajaran dibutuhkan orientasi literasi baru menuntut bagi lulusan ke depan, yaitu: (1) literasi big bank data, mensyaratkan kemampuan membaca dan menganalisis informasi yang open source; (2) literasi teknologi, yaitu memahami cara kerja teknologi mesin aplikasi teknologi (coding, artificial intlegence, and engeenering principles). (3) Literasi kemanusian, yaitu humanities, komunikasi, disain (Aoun, 2017). Termasuk di dalamnya literasi karakter diri. Dibekali pula ketrampilan antara lain: (1) ketrampilan leadership, (2) ketrampilan team work, (3) Kelincahan dan kematangan budaya (cultural agility) atau pemahaman multikulturalisme, (4) ketrampilan entrepreneurship, termasuk social entrepreneurship; bahkan body entrepeniurship (cf. Error! Hyperlink reference not valid.). Dengan pikiran kritis dapat dipahami bahwa bangsa Indonesia adalah bangsa yang melampaui (belog ajum). Perlu pemahaman bahwa dengan teknologi dan industri 4.0 bukan berarti bangsa ini harus mengubah segalanya menuju digitalisasi dan industrialisasi otomatisasi, masih ada isi-sisi kehidupan yang tidak dapat dilakukan.

Dari perspektif motodologis sejarah, komputasi-awan dengan mesin penyelusurannya merupakan sumber data melimpah, hanya saja harus dikritisi kebenarannya, menggunakan teori kritis secara eklektik dan prinsip-prinsip cara kerja mesin komputasi awan. Langkah penulisan sejarah tetap dibutuhkan untuk judgment kebenaran informasi. (1) Literasi data ikipedia, kritik, dan interpretasi dengan teori kritis secara eklektik ditambah pemahaman kerja mesin (kecerdasan artificial) sehingga dapat judgment yang mendekati kebenaran. (2) Literasi kemanusiaan jangan dilupakan karena hidup membutuhkan nilai-nilai kemanusiaan. Manusia memiliki nafsu, kehendak, dan rasa kompetitif tinggi, bahkan cenderung homo homini lupus, dan serakah. Maka dari itu perlu peserta didik dibekali literasi karakter dengan pemahaman hasrat inti manusia yaitu: hasrat berkuasa/politik, hasrat kebutuhan biologis (libido seksualitas), dan hasrat ekonomi (inti modernitas). (4) Literasi teknologi komputasi awan (kerja mesin/computer) agar dapat dipahami dengan baik, sehingga ikipedia/kesadaran palsu yang dibangun melalui dunia maya dapat ditelanjangi dengan baik, sehingga kesadaran palsu dan bentuk penipuan lainnya karena hasrat dan nafsu kapitalis manusia dapat dipahami.

Pendidikan sejarah adalah jalan terbaik untuk mengantisipasi era milenial yang diwarnai oleh ekonomi pasar atau modal, uang menjadi agama (from monotheism to moneytheism). Tanpa dibekali pemikiran kritis menggunakan kearifan lokal/regional maka manusia Indonesia mudah 
tercabut akarnya, bahkan menjadi generasi kehilangan kerakter, sehingga sejarah nasional dan lokal dipentingkan (Bourdieu dalam Damsar, 2011).

Teknologi mempasilitasi nafsu melakukan penjualan serba digital dan serba otomatis, membobol dinding-dinding tebal negara (borderless state), dan menembus dinding tebal sekatsekat struktur-kultur, agen, dan waktu saat ini, dapat dibobol dengan "komputasi awan". Kalau pendidikan sejarah "ingin tetap diadakan atau tidak hanya menjadi beban kurikulum" maka adaptasi, hibridasi industri teknologi komputasi awan harus diperdayakan dalam pembelajaran sejarah. Dengan demikian pendidik harus mempu mengoperasikan komputasi dengan berbagai program kecerdasan buatannya, untuk mengisi isi dagangannya berupa "dokumen, gagasan sejarah, peristiwa sejarah, dan nilai-nilai sejarah dengan berbagai tematiknya", bentuknya bisa tulisan, video, film, hasil wawancara dengan tokoh, dan peristiwa menarik lainnya.

Implikasinya pembelajaran dilakukan dengan menggunakan bank big data internet (literasi data) dalam pembelajaran, mensyaratkan peserta didik memiliki perangkatnya (computer, android, serta paket link-nya), diarahkan sumber-sumber belajar yang diakses, ditugaskan melakukan digitalisasi, video, animasi (flash), dan ketrampilan lainnya secara berteam, sehingga terjadi pembelajaran kolaboratif. Situs dibuat dan dijadikan ajang untuk menjual idea, gagasan, hasil belajar (film pendek, video documenter, dll) yang sangat bermanfaat bagi masyarakat dan dirinya dalam bekerja ke depan. Dengan demikian tidak ada pekerjaan peserta didik yang sia-sia, dalam mendukung profesionalismenya ke depan. Baik berupa data yang terkumpul (diotomatisasi), proses yang dibuatkan langkah-langkah (Standard Operational Procces), dan hasilnya disimpan secara digital, menjadi kekayaan intelektual secara individual atau kolaboratif.

Model pembelajaran sejarah masa depan seperti diuraiakan di atas harus memenuhi syarat-syarat (necessary conditions):

1. Perangkat komputasi, android, dan link internet harus memenuhi standar minimal.

2. Pendidik dan Peserta didik paham tentang teknologi informasi (TI) dan sistem komputasi awan.

3. Memiliki akun server di dunia maya, sebagai alat simpan kekayaan intelektual yang dapat diakses oleh guru dan peserta didik. 
4. Perlindungan mesin simpan (reserver), dan kepastian kepemilikan hasil karya (film, Video, dan documenter lainnya).

5. Belajar dan pembelajaran bukan hanya di kelas, tetapi lebih banyak tugas-tugas dikerjakan secara daring (waktu tidak terbatas).

6. sistem quality control bidang ilmu pendidikan sejarah, sebagai legitimator keabsahan bank data yang tersimpan.

7. Penilaian ada pada out put dan out come karya peserta didik, dengan perspektif (literasi data, literasi kemanusiaan, literasi karakter, literasi teknologi/industri 4.0) dan mungkin tambahan muatan lokal perpektif THK di Bali.

Pembelajaran sejarah berbasis komputasi awan ini, adalah jalan terbaik untuk antisipasi pendidikan sejarah di masa depan, di era disruksi teknologi dan industri 4.0, hanya saja kondisi bangsa Indonesia dewasa ini masih sangat timpang sehingga masih jauh tampaknya dapat diterapkan di seluruh Indonesia, tetapi dalam pembelajaran yang memenuhi necessary conditions di atas, terutama di beberapa sekolah di Bali sangat mungkin untuk dilakukan.

\section{Simpulan}

Tantangan pendidikan sejarah di era milenial, butuh bekal teknologi dan industri otomatisasi menggunakan komputasi awan maka pendidikan sejarah. Pembelajaran sejarah harus mampu mengadaptasi, melakukan hibridasi berbagai teknologi, sistem dan model kerja industri 4.0 di era milenial, kalau sejarah tidak mau ditinggalkan di era milenial. Beberapa prinsip dasar pembelajaran sejarah inovatif konstruktif, antara lain: (1) menekankan sasaran proses belajar berorientasi ke masa depan yang diwarnai oleh digitalisasi dan industri otomatisasi era milenial; (2) Pendekatan ketrampilan proses dan out put dengan pemanfaatan teknologi komputasi awan, dan pembuatan produk digitalisasi (video,film, documenter, dll), menekankan aktivitas dan kreativitas peserta didik ; dan (3) Pembelajaran yang lebih menekankan proses belajar internalisasi nilai sejarah, dengan usaha peserta didik untuk menemukan konsep-konsep serta struktur-struktur dasar dari gambaran peristiwa masa lampau, kemudian melakukan digitalisasi, penyimpanannya, dan industrialisasi secara mandiri (entrepreneurship) untuk memetakan masa depannya. (4) Dibutuhkan kemampuan literasi big data di dunia maya, literasi kemanusiaan, literasi karakteri, literasi teknologi komputasi awan, dan proses (alat selusur) dan konsekuensi 
penggunaannya. Tanpa landasan-landasan pikiran pembaharuan seperti ini, dapat diasumsikan pendidikan sejarah akan kehilangan makna dan hanya menjadi beban kurikulum di masa depan.

\section{DAFTAR PUSTAKA}

Adam, Asvi Warman. 2009. Membongkar Penipulasi Sejarah: Kontroversi Pelaku dan Peristiwa. Jakarta: Kompas.

Ankersmit, F.R. 1987. Refleksi Tentang Sejarah:Pendapat-pendapat Modern Tentang Filsafat Sejarah. Dick Hartoko (penerjemah). Jakarta: Gramedia.

Bruner, Jerome S. 1960. The Process of Education. New York : Vintage Books

Carr, E.H. 1972. What is History. New York: Alfred A. Knopf.

Collingwood, R.G. 1980. The Idea of History. London: Oxford University.

Damsar, 2011. Pengantar Sosiologi Pendidikan. Jakarta: Kencana Prenada Group.

Fenton, Edwin (ed). 1966. Teaching the Social Studies in Secondary Schools: An Inductive Approach. New York: Carnegie Mellon Univ.

Fitzgerald, James. 1983. "History in the Curriculum : Debate on Aims and Values", dalam History and Theory XXII, 4, hal. 81-100.

Giddens, Anthony.2010. Teori Strukturasi: Dasar-dasar Pembentukan Struktur Sosial Masyarakat. Jogjakarta: Pustaka Pelajar.

Kartodirdjo, Sartono. 1987. "Kemanakah Sejarawan Indonesia: Legitisme, Rekonstruksionisme, dan Futurisme", dalam Sartono Kartodirdjo, Kebudayaan, Pembangunan dalam Perspektif Sejarah. Yogyakarta: Gajah Mada University Press.

. 1990. "Kesadaran Sejarah dan Kepribadian Nasional", artikel di Harian Kompas, 4-5 Oktober 1990, hal. IV.

Kompas, 1990. Menuju Masyarakat Baru Indonesia: Antisipasi Terhadap Tantangan Abad XXI. Jakarta: PT. Gramedia.

Krug, Mark M. 1967. History of the Social Sciences: New Approach to the Teaching of Social Studies. Mass.: Waltham.

Laue, T.H. Von. 1981. "What History for the Year 2000”, dalam The History Teacher, Vol. 15, No. 1, hal. 7-23.

277 | Seminar Nasional Sejarah ke 4 Jurusan Pendidikan Sejarah Universitas Negeri Padang 
Meulen SJ., W.J. van der. 1987. "Pengajaran Sejarah Dewasa ini”, dalam Ilmu Sejarah dan Filsafat. Yogyakarta: Kanisius.

Moertopo, Ali. 1978. Strategi Kebudayaan. Jakarta: Yayasan Proklamasi.

Naisbitt, John, Aburdeen, Patricia. 1990. Megatrends 2000: Sepuluh Arah Baru untuk Tahun 1990-an (terjemahan Drs. F.X. Budiyanto). Jakarta : Binarupa Aksara.

Naisbitt, John.1982. Megatrends: Ten New Directions Transforming Our Live. New York: Warner Books Inc.

Pageh, I Made. 2016. “Genealogi Baliseering: Membongkar Ideologi Kolonial Belanda dalam Pendidikan di Bali Utara dan Implikasinya di Era Glonalisasi”. Disertasi. S-3. Denpasar: Universitas Udayana (Unpublish).

Pirenne, Hendry. 1959. "What Are Histrians Trying to Do", in Hans Meyerhoff (ed.) Philosophy of History in Our Time. New York: Doubleday Anchor Books.

Rogers, P.J. 1972. "History", dalam K. Dixon (ed.), Philosophy of Education and the Curriculum. London: Oxford University Press.

Surakhmad, Winarno. 1970. Mencari Strategi Pembinaan Pendidikan Pembangunan Dewasa ini. (Tanpa nama dan tempat penerbit).

Toffler, Alvin. 1970. Future Shock. London: Pan Books Ltd. .1982. The Third Wave. New York : Bantam Books Inc.

Toynbee, A.J. 1947. A Study of History (Abridgement by D. Somervell). London: Oxford University Press. . 1988. Menyelamatkan Hari Depan Umat Manusia (terjemahan Nin Bakdi Sumanto). Yogyakarta: Gajah Mada University Press.

Widja, I Gde. 1989. Sejarah Lokal: Suatu Perspektif dalam Pengajaran Sejarah. Jakarta: Dep. P dan K (P2LPTK).

Wineburg, Sam. 2006. Berpikir Historis: Memetakan Masa Depan, Mengajarkan Masa Lalu. Masri Maris (Penerjemah). Jakarta: Yayasan Obor Indonesia. 